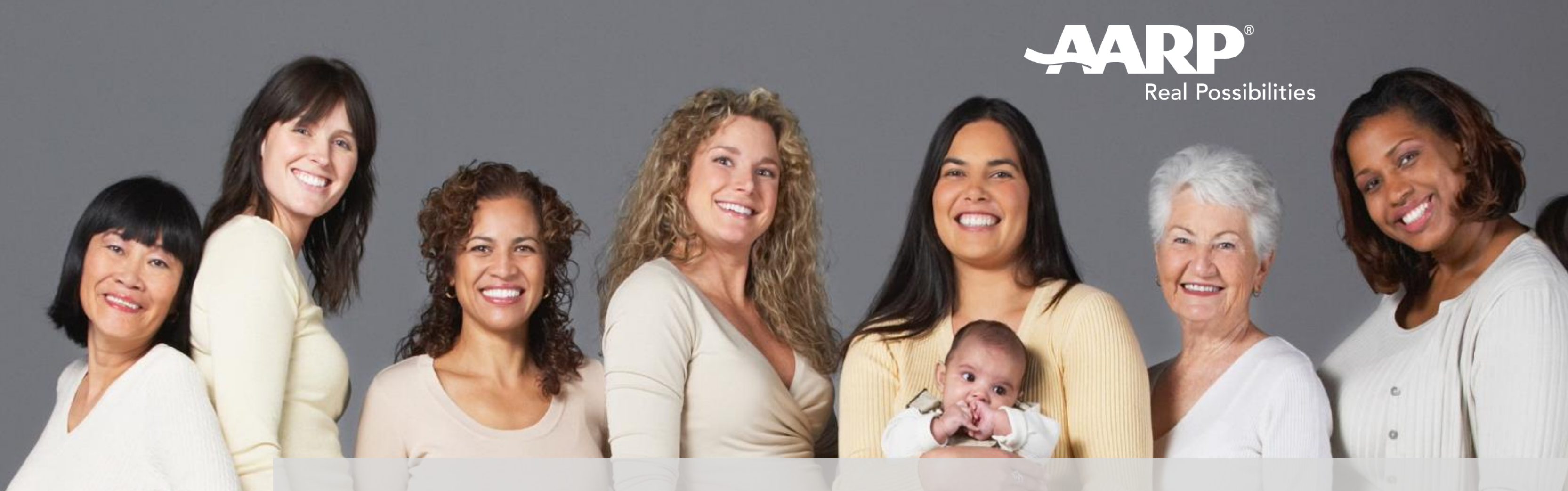

\title{
MIRROR/MIRROR: AARP SURVEY OF WOMEN'S REFLECTIONS ON BEAUTY, AGE, AND MEDIA ${ }^{\text {TM }}$
}




\section{Table of contents}

Executive Summary 3

Importance of Beauty 5

Definitions of Beauty 6

Investment in Beauty $\quad 12$

Unmet Beauty Needs $\quad 14$

Representation in the Media 18

Impact on Brands $\quad 24$

$\begin{array}{ll}\text { Appendix } & 29\end{array}$

Contact 32 


\section{EXECUTIVE SUMMARY}




\section{Executive summary}

- Beauty is important to women, and its importance does not diminish with age.

- Intrinsic definitions of beauty trump extrinsic definitions - and get even more prominent as women age.

- Women make a significant investment of time and money in beauty.

- Yet, as women age, they have unmet beauty needs.

- In fact, as women age, they are more likely to feel the beauty industry treats them as an afterthought, and they are less likely to see themselves represented in media.

- Across generations, women would like ads to have more age diversity and more authentic images.

- Women reward brands that promote real inclusion — including age. 
IMPORTANCE OF BEAUTY 


\section{Beauty is important to women, and its importance does not diminish with age.}

Overall, 89 percent of women say beauty and personal grooming are at least somewhat important to them (43 percent very important, 47 percent somewhat important).

How important if at all, is beauty and personal grooming to you?

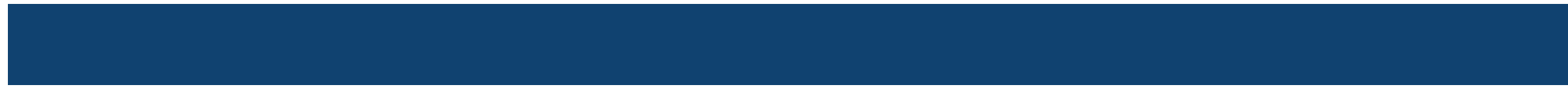

$89 \%$

Millennials

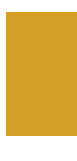

Gen X

$90 \%$ 


\section{Top definitions of beauty are more often intrinsic than extrinsic.}

There is consistency in the top three elements that define beauty — none of which include physical appearance.

What do you feel defines beauty? (aided)

\begin{tabular}{|c|c|c|c|c|}
\hline & 18+ Women & Millennials & Gen $X$ & Boomers \\
\hline Kindness & $49 \%$ & $44 \%$ & $46 \%$ & $58 \% \triangle$ \\
\hline Morals, character, values & $46 \%$ & $41 \%$ & $46 \%$ & $53 \% \triangle$ \\
\hline Personality & $45 \%$ & $43 \%$ & $43 \%$ & $46 \%$ \\
\hline Physical appearance & $28 \%$ & $21 \%$ & $30 \%$ & $32 \%$ \\
\hline Personal grooming & $17 \%$ & $15 \%$ & $18 \%$ & $18 \%$ \\
\hline Physical health & $14 \%$ & $14 \%$ & $15 \%$ & $15 \%$ \\
\hline Personal image & $14 \%$ & $16 \%$ & $16 \%$ & $10 \%$ \\
\hline Wellness & $11 \%$ & $14 \%$ & $11 \%$ & $8 \%$ \\
\hline Wisdom & $11 \%$ & $11 \%$ & $10 \%$ & $12 \%$ \\
\hline Mental health & $10 \%$ & $14 \% \Delta$ & $8 \%$ & $7 \%$ \\
\hline Perception of body image & $9 \%$ & $12 \%$ & $10 \%$ & $7 \%$ \\
\hline Personal fulfillment & $6 \%$ & $7 \%$ & $4 \%$ & $8 \%$ \\
\hline
\end{tabular}

"Compassion, love, nature, original, nonjudgmental."

- Millennial

"Confidence. Being true and honest with oneself without taking people down around you."

- Gen Xer

"Beauty is not a physical trait, but rather a personality trait."

- Boomer 


\section{Similarly, top motivations for focusing on beauty are intrinsic.}

Top motivations, which are intrinsic, are relatively consistent across generations. Some secondary motivations differ across generations.

How much does each of the following motivate you to focus on your own beauty and personal grooming?

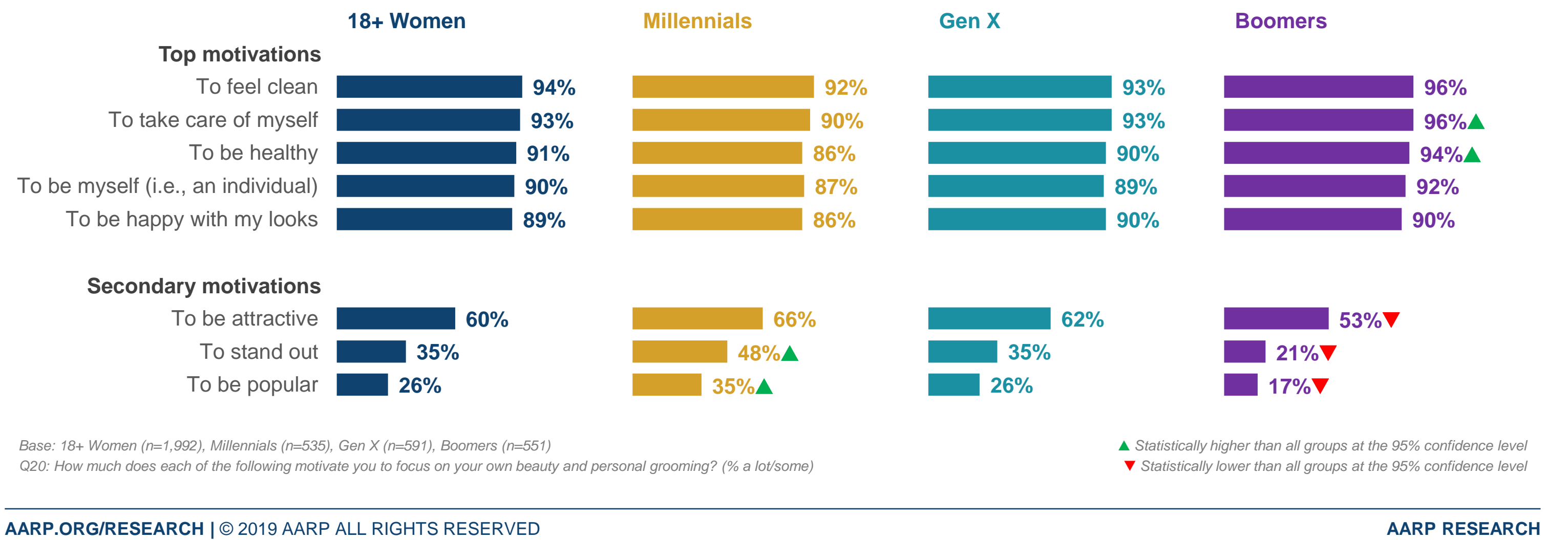




\section{As women age, the increased importance of inner beauty reflects}

the decreased importance of external motivations.

Agree that inner confidence is more important than outer beauty
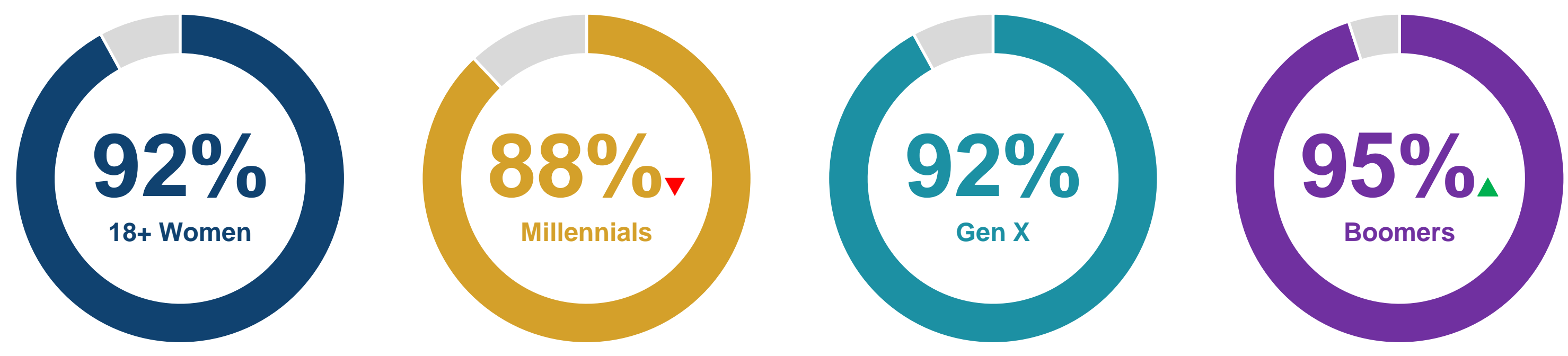


\section{Being healthy is a stronger motivator for women ages 50 and older than for those who are younger.}

How much does each of the following motivate you to focus on your own beauty and personal grooming?

To be attractive to others (strongly agree)

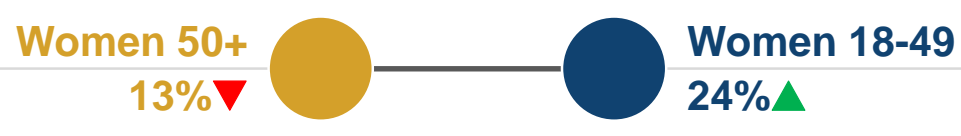



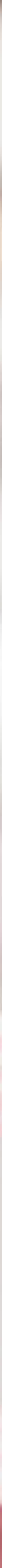

INVESTMENT IN BEAUTY

5

.

$=$

- 


\section{Women invest a significant amount of time and money in their beauty and personal grooming regimen.}

On average, women use six beauty and personal grooming products each day, devote at least 30 minutes per day to their beauty and personal grooming regimen, and spend $\$ 40$ per month on beauty and personal grooming products.

Number of products used each day

18+ Women

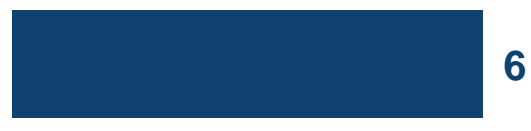

Millennials

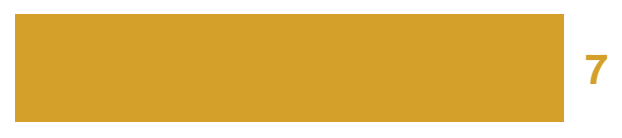

Gen X

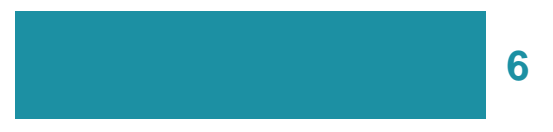

Boomers

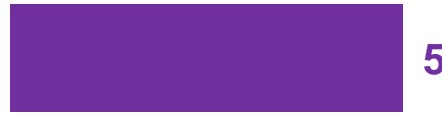

Spending in a typical month

$18+$ Women

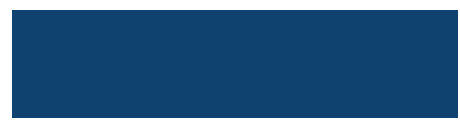

$\$ 39$

Millennials

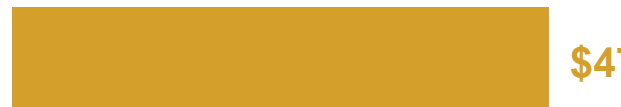

Gen X

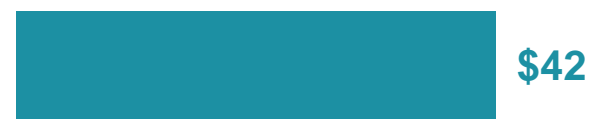

Boomers

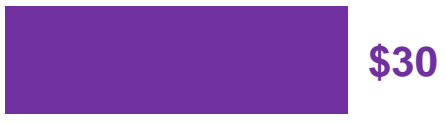

$\$ 30$
Minutes spent per day

18+ Women

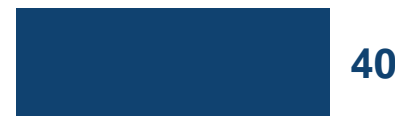

Millennials

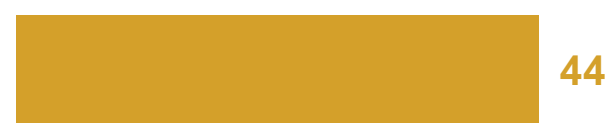

Gen X

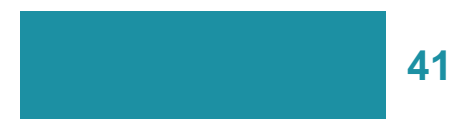

Boomers

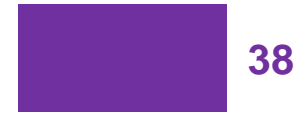




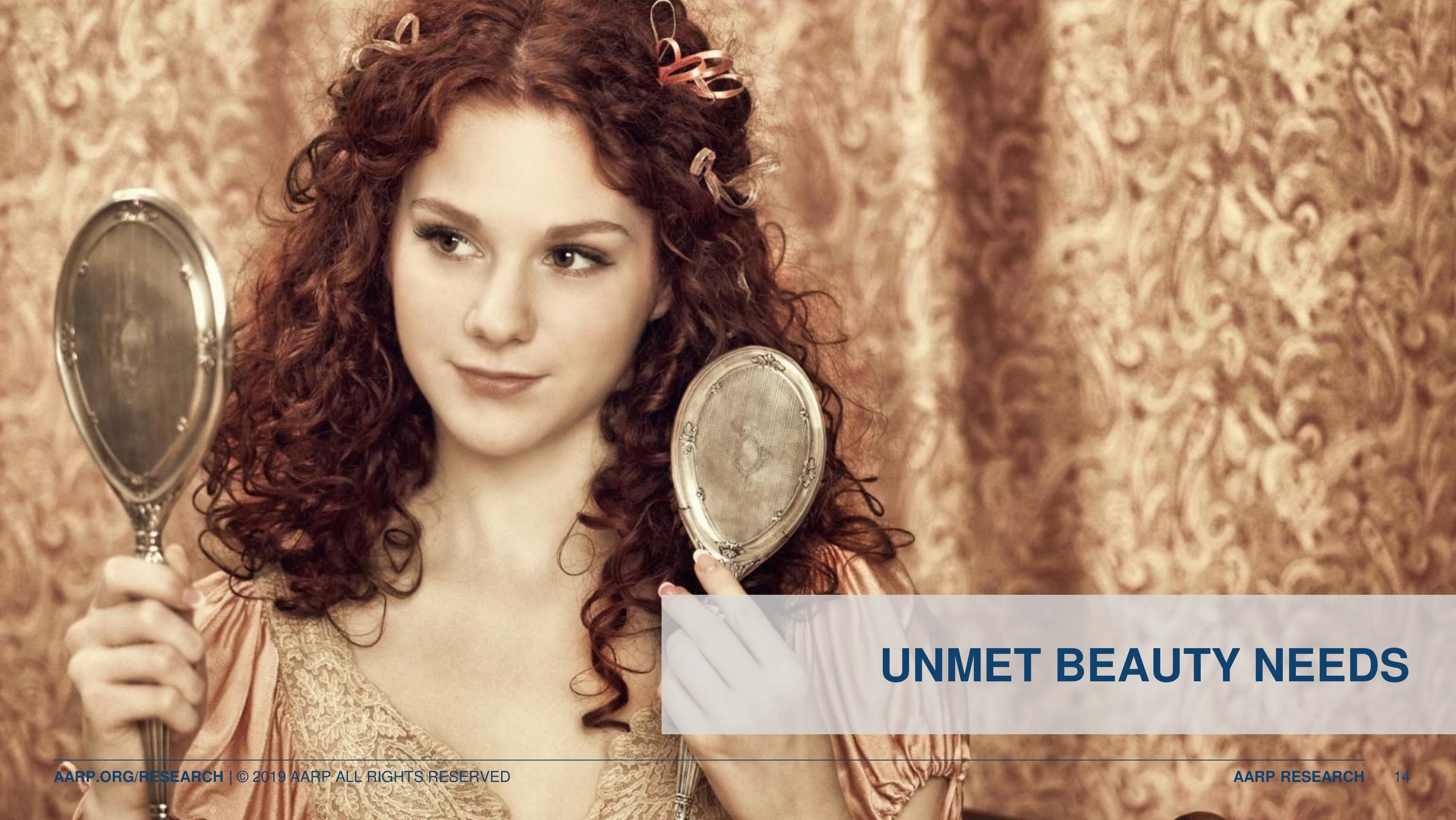




\section{As women age, they feel increasingly ignored by the beauty and personal grooming industry.}

Older women are more likely than younger women to feel ignored by the beauty and personal grooming industry.

$\%$ who feel the beauty and personal grooming industry does not create products with people my age in mind
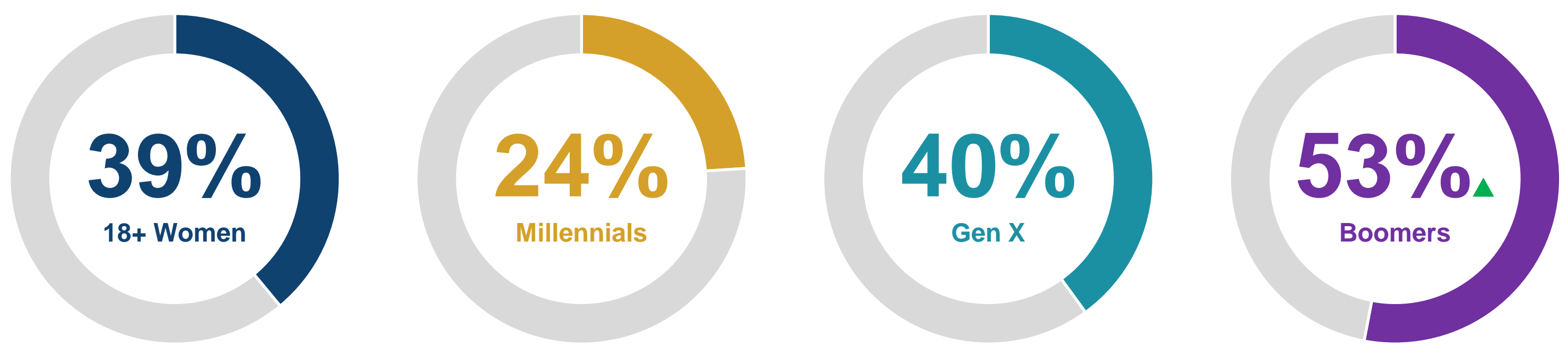


\section{Women ages $\mathbf{5 0}$ and older have difficulty finding products tailored to their age.}

Those under age 50 are more likely to use home remedies and to turn to social media for solutions.

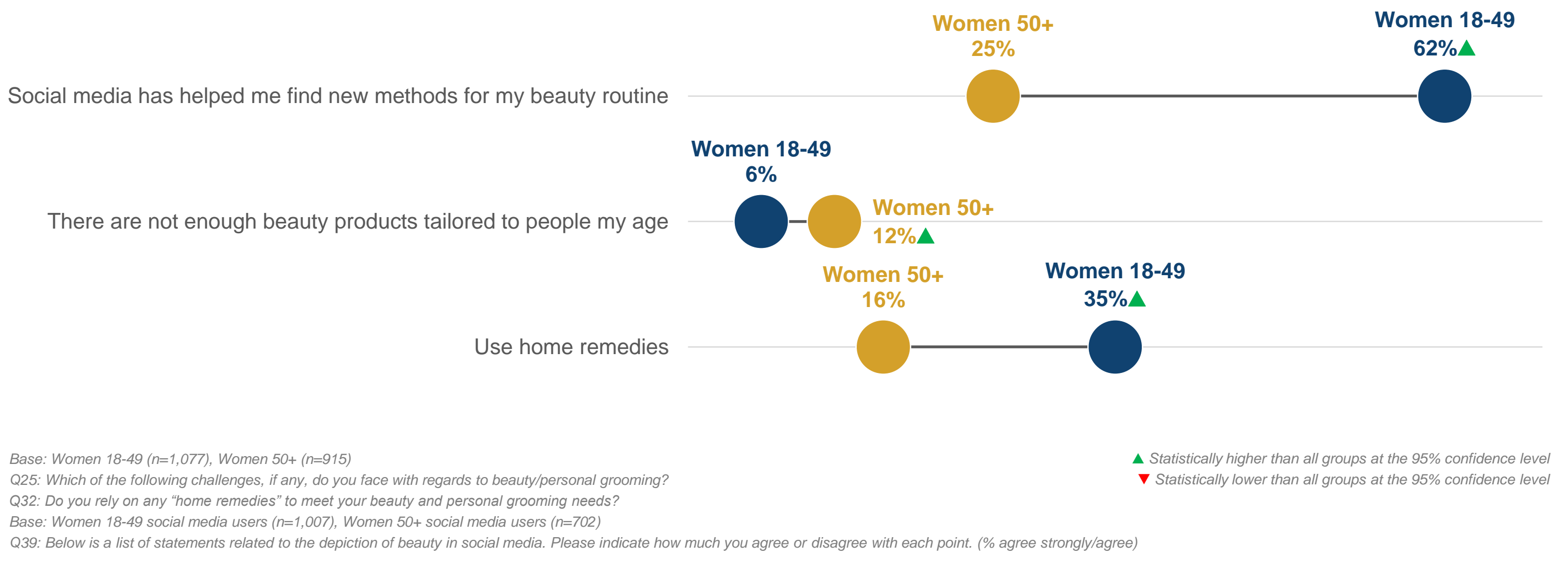




\section{Women 40 and older have unmet beauty and personal grooming product needs related to perimenopause and menopause.}

$70 \%$ of women ages $40+$ want to see more perimenopausal and menopausal beauty and personal grooming products.

Products women want to see more of in relation to perimenopause and menopause

Total $40+$

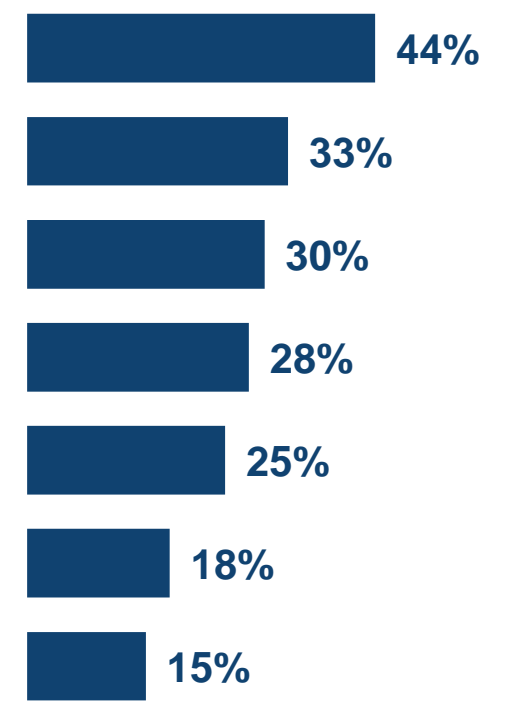

Gen X

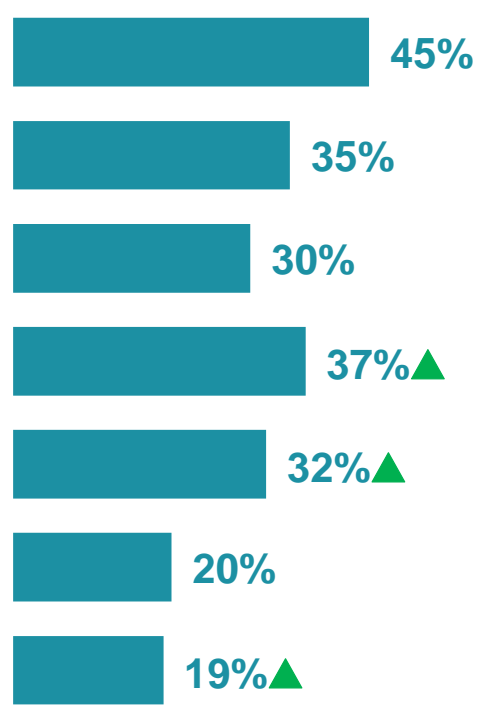

Boomers

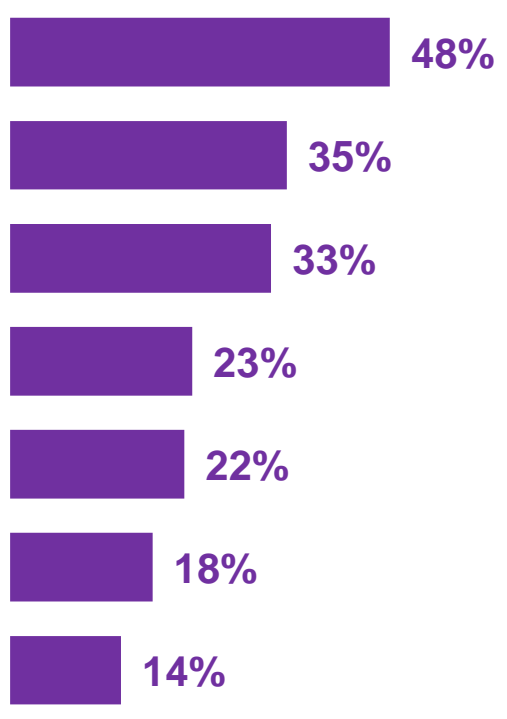




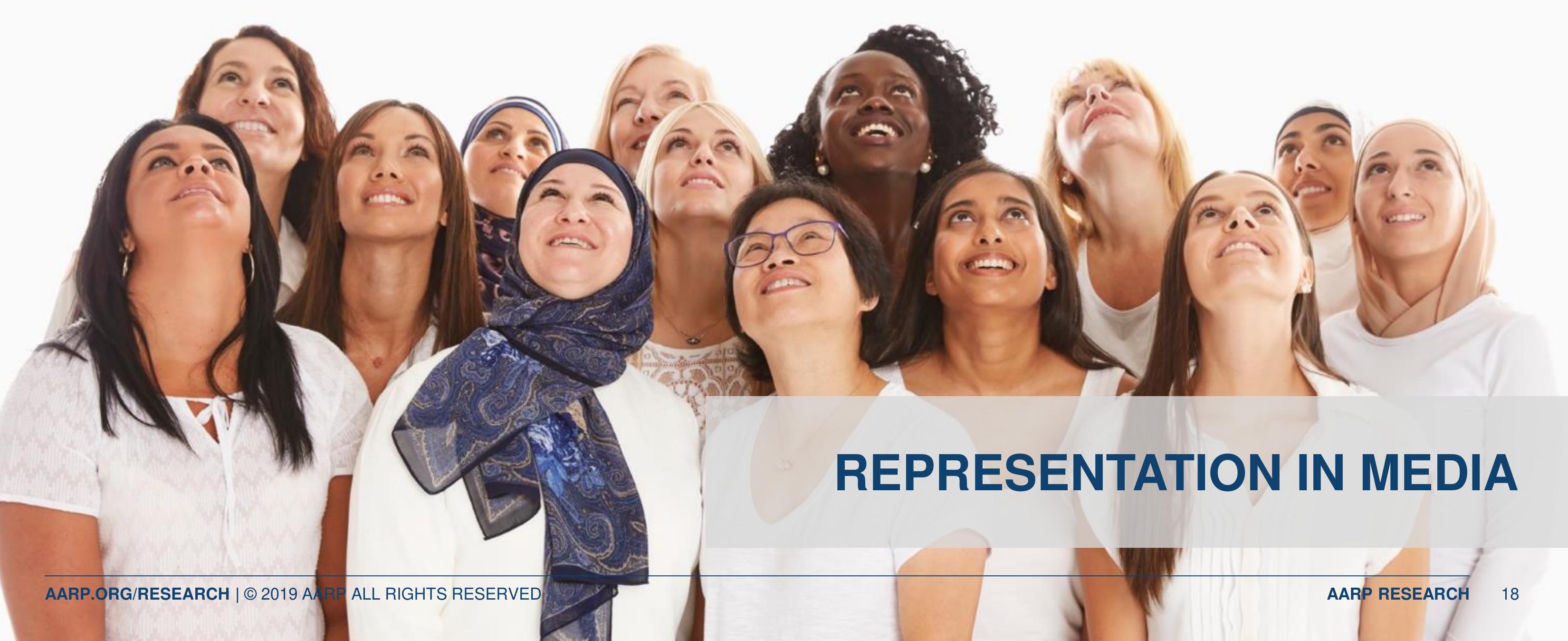




\section{Women across generations agree that older adults are not adequately represented in advertising.}

Feel representation of older adults in advertising is inadequate
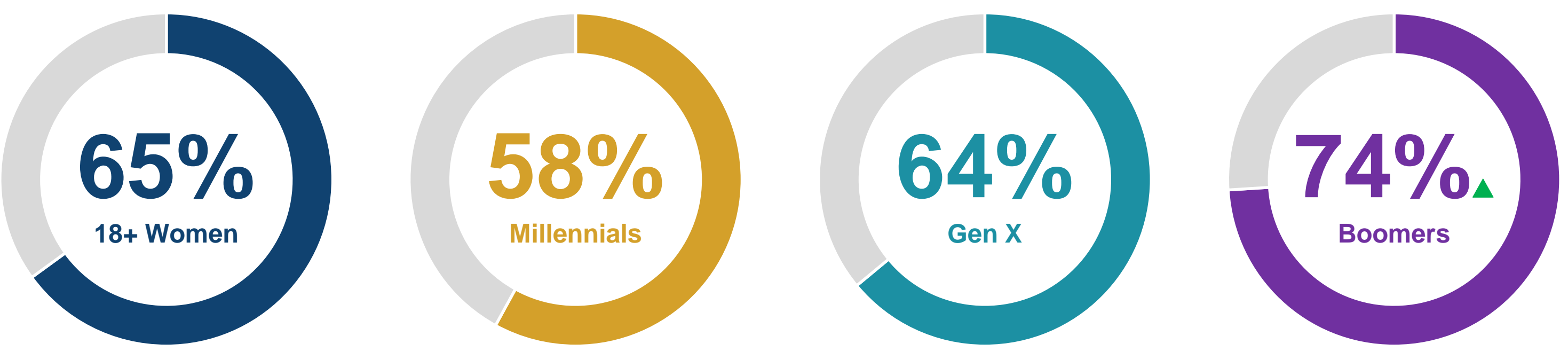


\section{Boomers feel most underrepresented in media imagery.}

Feel people their age are underrepresented in media imagery
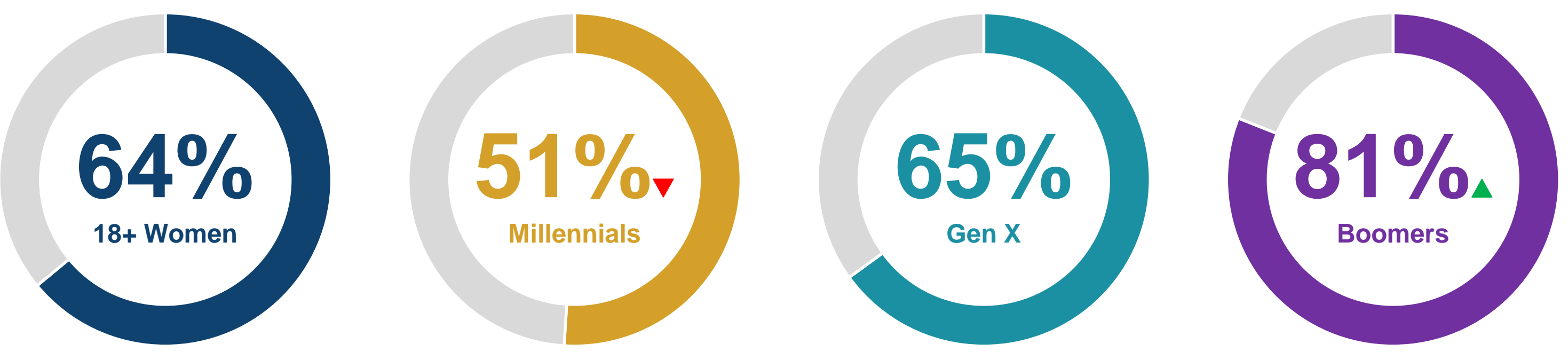


\section{Boomers are also most likely to feel like the beauty and personal grooming industry treats them as an afterthought.}

The beauty and personal grooming industry treats people my age as an afterthought
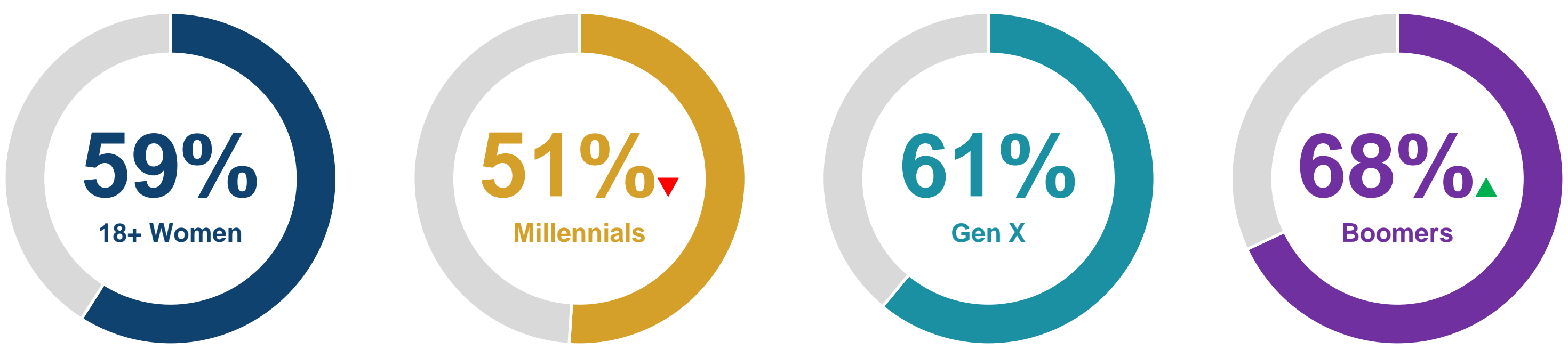


\section{Women want ads with more realistic images of people.}

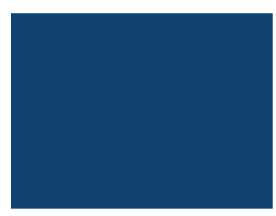

$85 \%$

Wish ads had more realistic
images of people

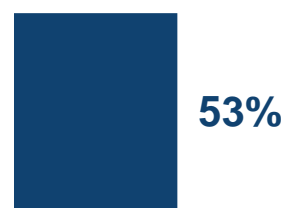

Say media images of people make them feel unattractive

Feel seeing beauty and personal grooming ads with real people makes them feel

better about themselves
Millennials

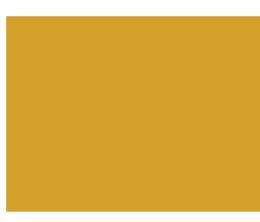

$83 \%$

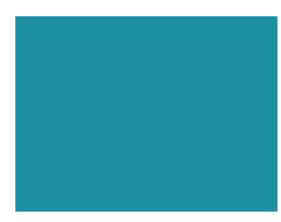

$85 \%$
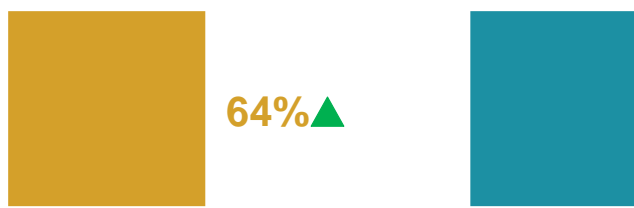

$54 \%$

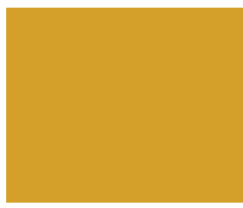

$78 \%$

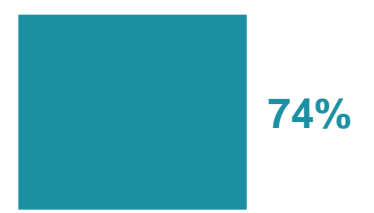

Boomers
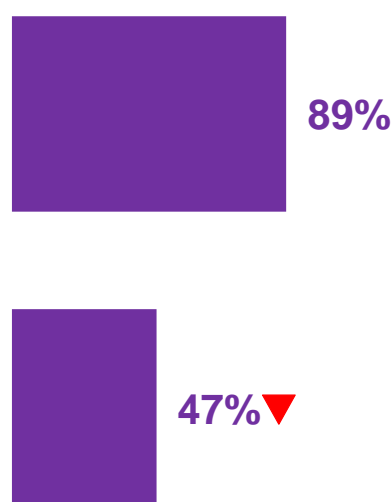

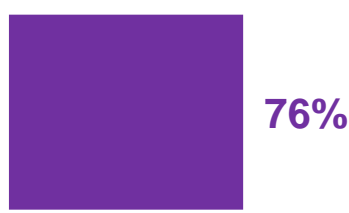




\section{The beauty industry gets a mediocre grade for age representation.}

The majority of women feel that media images in general are ageist $(69 \%$ total women, $64 \%$ Millennials, $70 \%$ Gen Xers, $74 \%$ Boomers). As women age, they are more likely to grade the beauty and personal grooming industry with a $\mathbf{C}$ or worse for representing people their age in its ads.

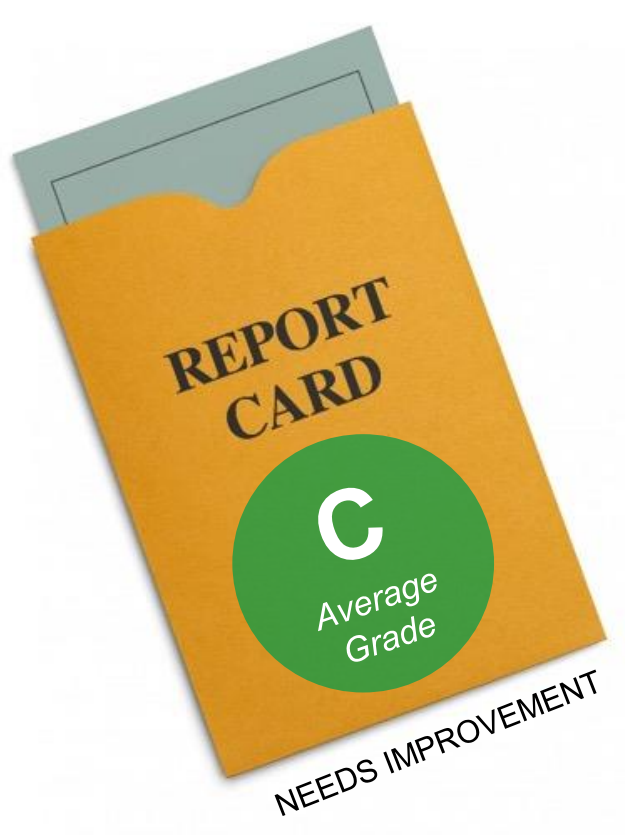





\section{Women reward brands that feature age diversity and inclusion.}

Brands can deepen emotional connections with consumers and potentially increase revenue as well.

Feel better about brands that

feature a mix of ages in their

ads

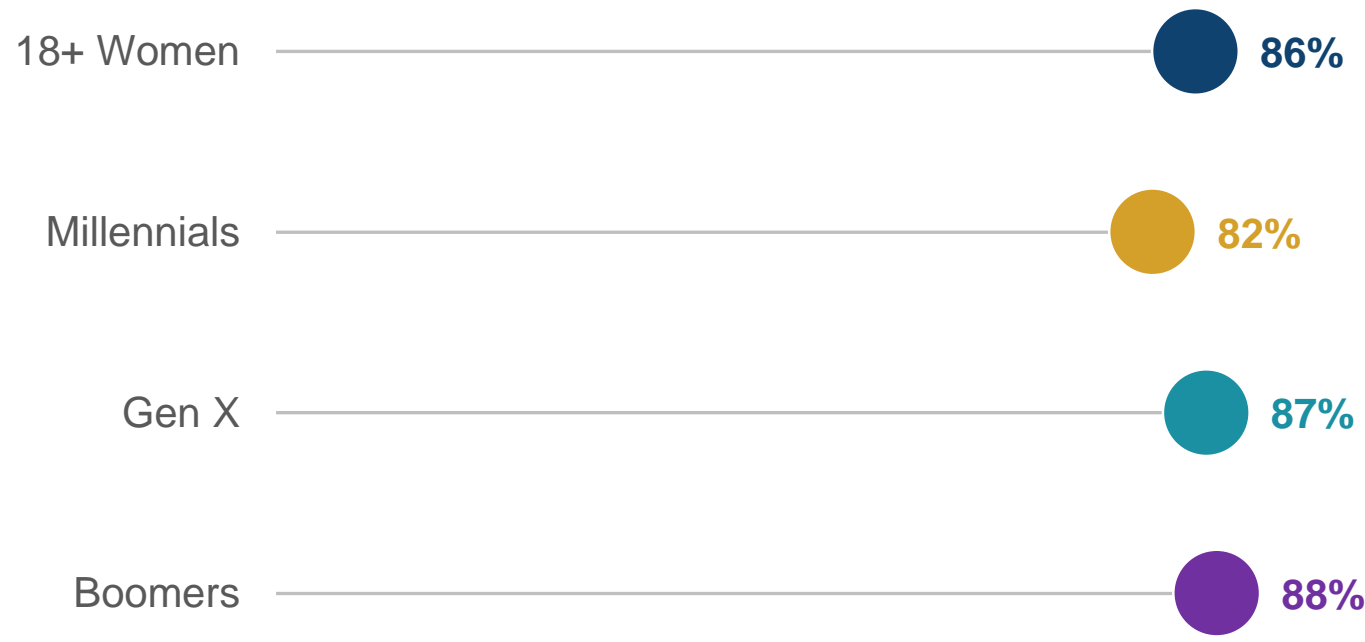

More likely to buy from

brands that feature a mix of

ages in their ads

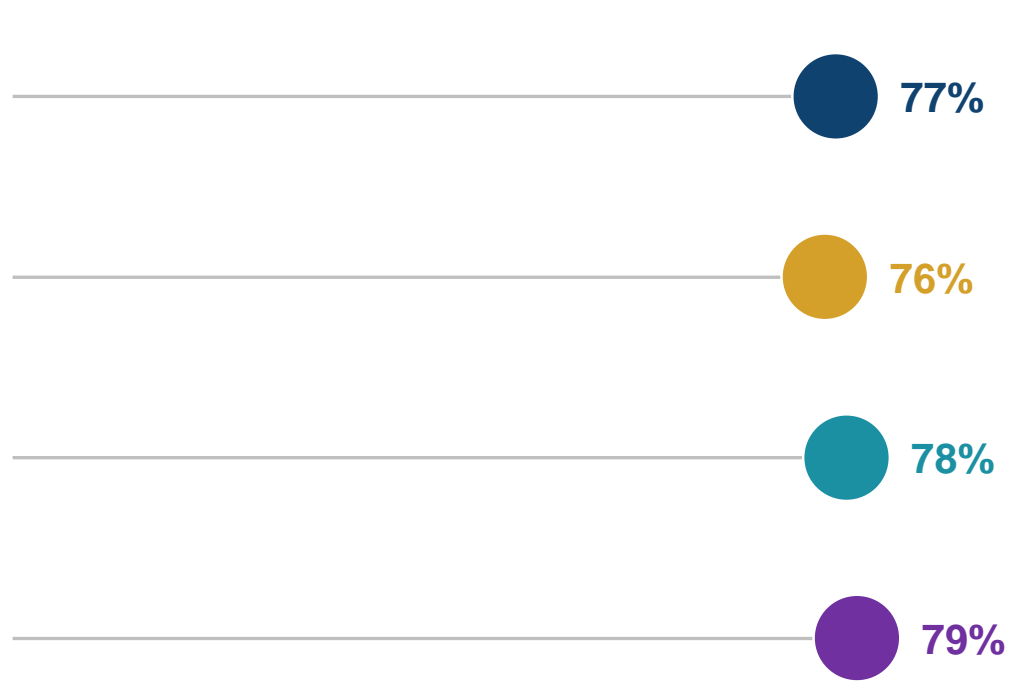




\section{Women's desire for inclusivity is not limited to age.}

Feel better about brands that

feature a mix of races and ethnic

identities in their ads

Feel better about brands that

feature people with different body

shapes in their ads
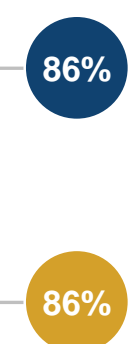

$86 \%$

$89 \%$

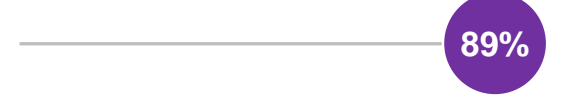

More likely to buy from brands that feature a mix of cultures and backgrounds in their ads
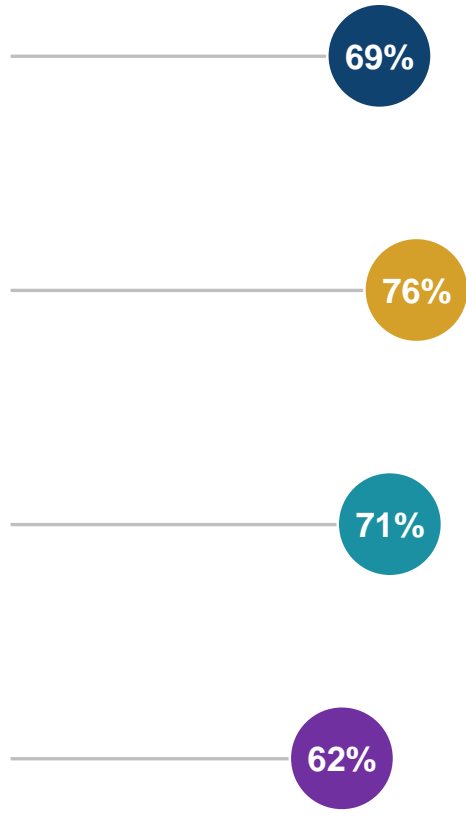

More likely to buy from brands that feature people with different body shapes in their ads
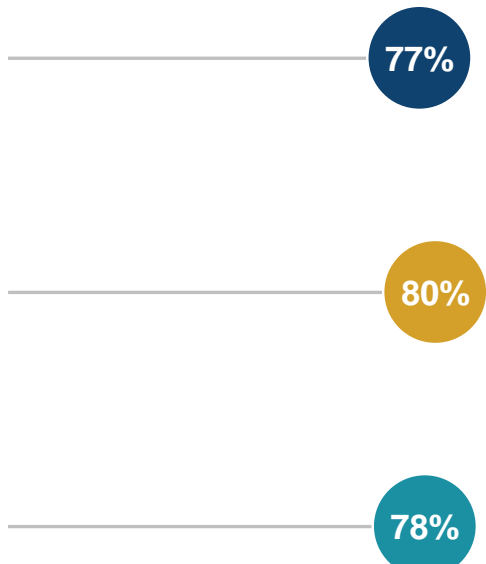

$78 \%$ 


\section{Across generations, women show loyalty to brands that represent people their age.}

$$
\begin{aligned}
& \text { More likely to recommend } \\
& \text { brands that feature people } \\
& \text { their age in their advertising }
\end{aligned}
$$

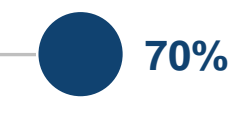

Millennials

Gen X

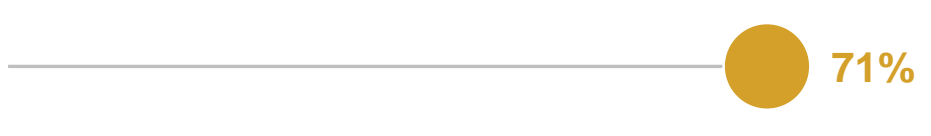

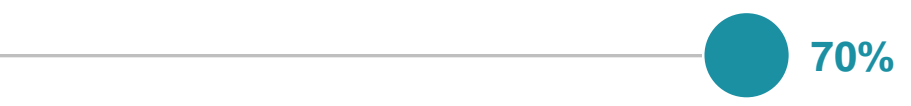

Boomers

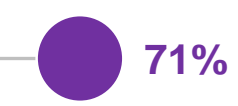

Would consider switching to a brand they feel represents

their age

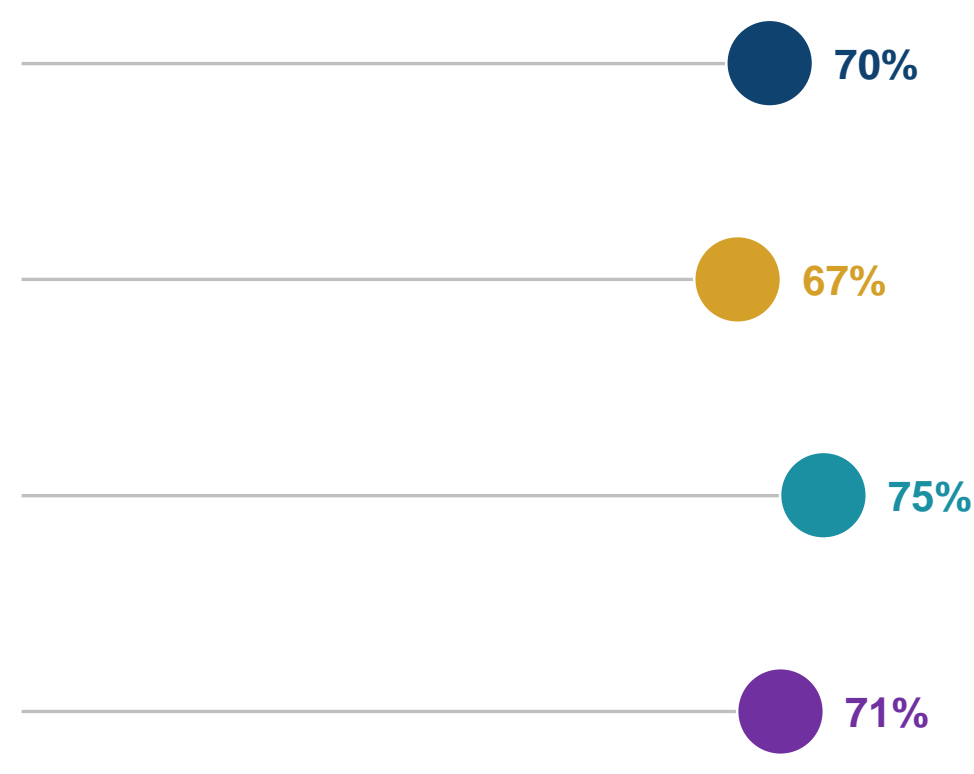




\section{While social media holds promise, it also carries pressures.}

Among social media users

18+ Women

Millennials

Gen X

Boomers

Positives of social media

Social media has helped me find new methods for my beauty and personal grooming routine

Social media is changing my perception of beauty and personal grooming for the better

Social media is moving consumers away from the norm of air-brushed advertisements
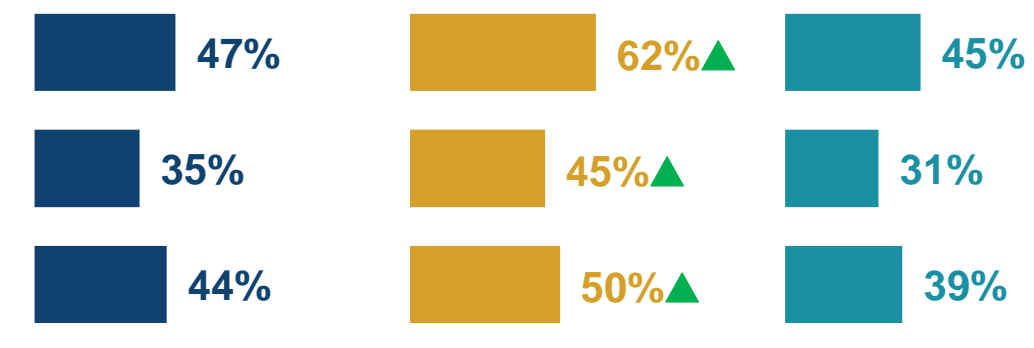

$24 \%$

$20 \%$

$44 \%$

Negatives of social media

I feel pressure to post good photos of myself on social media

I have edited a photo before posting it on social media to make myself look better

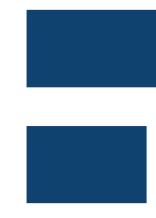

$47 \%$

$40 \%$

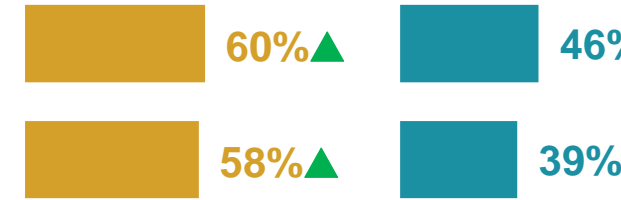

$46 \%$

$39 \%$
$32 \% \nabla$

$14 \% \nabla$ 


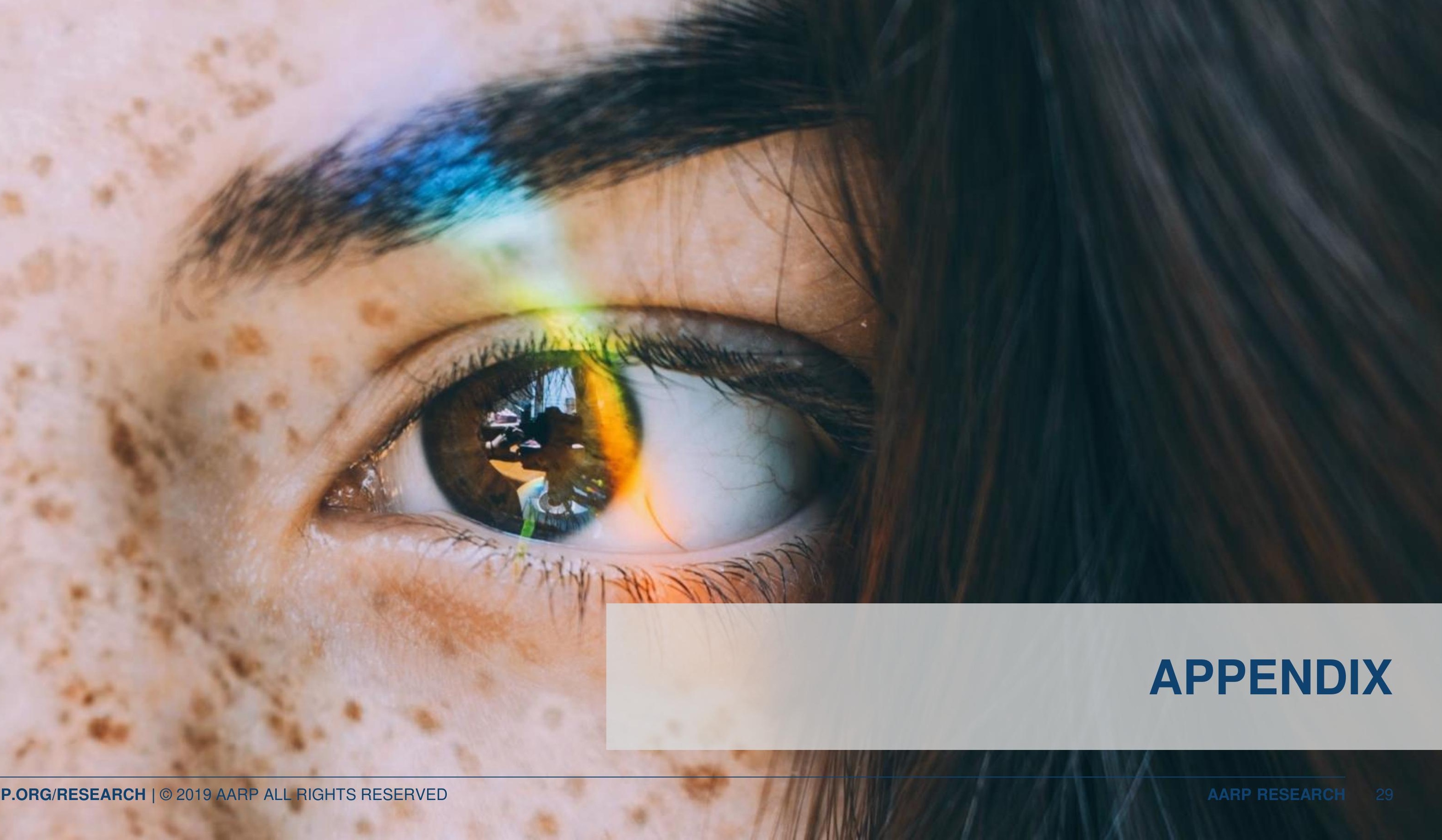




\section{Methodology}

An online survey of 1,992 women was conducted July 2-16, 2019, by Hotspex, Inc., using the Dynata panel supplemented by offline intercepts among unacculturated Hispanics/Latinos. The data were weighted by age, region, education, and ethnicity to reflect U.S. women ages 18 and older. The margin of error associated with a $95 \%$ confidence interval for the total sample is $+/-2.5 \%$.

The following definitions were used for each generation:

- Millennials: Ages 22-38

- Gen X: Ages 39-54

- Boomers: Ages 55-73 


\section{About AARP}

AARP is the nation's largest nonprofit, nonpartisan organization dedicated to empowering Americans 50 and older to choose how they live as they age. With nearly 38 million members and offices in every state, the District of Columbia, Puerto Rico, and the U.S. Virgin Islands, AARP works to strengthen communities and advocate for what matters most to families with a focus on health security, financial stability and personal fulfillment. AARP also works for individuals in the marketplace by sparking new solutions and allowing carefully chosen, high-quality products and services to carry the AARP name. As a trusted source for news and information, AARP produces the nation's largest circulation publications, AARP The Magazine and AARP Bulletin. To learn more, visit www.aarp.org or follow @AARP and @AARPadvocates on social media.

\section{About Hotspex, Inc.}

Hotspex Inc. is a full-service market research company with one purpose: to help brands grow. Founded in 2000, Hotspex has conducted research in 34 countries around the world. Hotspex operates globally, with offices in Toronto, New York and London. For more information, visit Hotspex's website at www. Hotspex.com. 


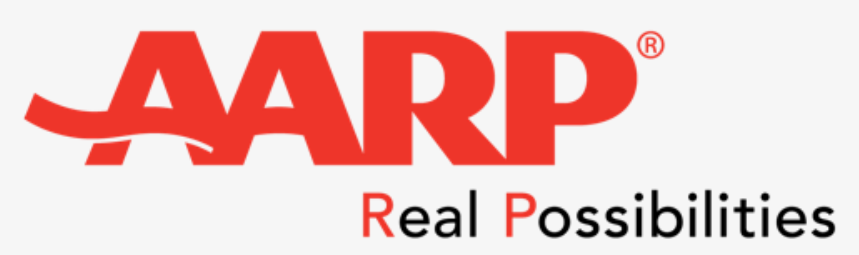

Colette Thayer, PhD., AARP Research cthayer@aarp.org

Angela Houghton, AARP Research ahoughton@aarp.org

For media inquiries, please contact media@aarp.org 